\title{
Synthetic Risk Evaluation Index System of Carbon Finance in Commercial Banks in China
}

\author{
Wenjuan $\operatorname{Pan}^{1}$ \\ ${ }^{1}$ School of Economics, Northwest University for Nationalities, Lanzhou, China \\ Correspondence: Wenjuan Pan, School of Economics, Northwest University for Nationalities, Lanzhou 730124, \\ China. E-mail:wjpcn@126.com
}

Received: June 22, 2014

Accepted: July 4, 2014

Online Published: July 15, 2014

doi:10.5430/ijba.v5n4p85

URL: http://dx.doi.org/10.5430/ijba.v5n4p85

This work was supported by the Fundamental Research Funds for the Central Universities of Northwest University for Nationalities (Grant No.31920140026).

\begin{abstract}
In this paper, the author analyzed the synthetic four dimensional evaluation index systems on risk of carbon finance in commercial banks in China. The analysis was conducted by means of an AHP-based Fuzzy Approach which builds a system analysis technique for multiple criteria decision making, and by market risk, credit risk, operational risk and project risk. The result show that evaluation index system based on AHP-based Fuzzy Algorithm for synthetic risk evaluation index system of carbon finance in commercial banks in China has good reliability.
\end{abstract}

Keywords: carbon finance, commercial banks, risks, AHP- fuzzy

\section{Introduction}

In order to mitigate the impacts of the subprime mortgage crisis in 2007, the world must try to find new methods for recovering the economy in coming stage. The appearance of low-carbon economic just satisfies the need of these countries. It has already become the important chance to achieve the goal of sustainable development. After the promulgation of "Kyoto Protocol", the demand for carbon emission right fostered greatly and the carbon market enlarged considerable. The right of carbon emission derivates to a financial asset which is worth to invest.

In China, carbon finance has promising developing perspective. With huge demand and potential profit, many financial institutions take part in different intermediate business. Based on the statistics by the World Bank during the years of 2006, 2007 and 2008, clean development mechanism in China has increased gradually from 54\%, 73\% and $84 \%$, which are higher than the level of developing countries by a great extent. If enterprises in China are unable to follow the trend of international finance, change business strategy to develop carbon business, our commercial banks will lose the opportunity to become one member of the standardized international banking fields as well as binding up its competitive power towards rivals. China is one of the biggest countries which elisions greenhouse gases. It determined that the potential market of carbon business is huge. As a result of all mentioned above, necessity of preparing positively for launching carbon business is strategic importance.

After the sub-loan crisis in 2007, many countries started to intensify the supervision for financial institutions as well as the self-realizing of the importance of avoiding risks. However, commercial banks, the main source of fund supply, are difficult to avoid risks when be involved in green credit business of gaining benefit. As an innovation, carbon business is relating to institutional risks with the unpredictable elements and unstable policies. When encountering policy and market risks, the priority of inner control is the theory which should be established at first. Therefore, more and more commercial banks are launching carbon business and paying great attention to risk controlling simultaneously. For the commercial banks in China, because of the shortage of related qualified personnel and stable policies, carbon business is still a business with high risk and uncertain return. Without effective managements and regulations, the economic losses which are bringing by the potential risk for commercial banks, even to the whole macro economic in China, is beyond imagination. The rest of this paper is organized as follows: Section 2 establishes the index evaluation system. Section 3 introduces the implementation of evaluation Algorithm on Fuzzy-AHP. Evaluation process and empirical analysis is discussed in Section 4. Finally, Section 5 concludes the paper. 


\section{Establishment of Evaluation System}

\subsection{Evaluation Procedure}

Analytical hierarchy process (AHP) was put forward by T.L.Saaty in 1970's. The method was a multiple decision-making method which combined qualitative with quantitative analysis. It could effectively analyze the non-sequential relationship between levels of target criteria system and effectively measure the judgment and comparison of decision-makers. However, conventional AHP did not truly reflect cognitive problem especially those "fuzzy" problems. "Fuzzy Analytic Hierarchical Process" (FAHP) Algorithm is designed to an alternative selection and justification problem by integrating the concept of fuzzy set theory and hierarchical structure analysis. The fuzzy AHP was able to solve uncertain problems and to rank excluded factors according to their weight ratios. The main steps of FAHP in ethnic regions were: 1) Establishing the index system; 2) Determinating evaluation set; 3) Establishing relative importance index; 4) Constructing judgment matrixes; 5) Calculating weigh value; 6) fuzzy comprehensive evaluation.

\subsection{Establishment of Evaluation Index System}

In the synthetic evaluation index system, The market risk refers to the risk of assets loss in commercial bank influenced by market factors of carbon finance, mainly including interest rate risk, exchange rate risk, CERs delivered price risk; The credit risk refers to the risks resulted from failure to fulfilling obligations or change of credit quality of counterparty in the process of investments on CDM projects in which the commercial banks engaged the carbon finance activities, including the risk of non-performing loans ratio of CDM project, contractual capacity on buyer, (real purchases of CERs/committed purchases of CERs), the risk of whether CDM projects put into operation on schedule and whether CDM projects generates the CERs risk under the contract; The operational risk: risk of personnel quality, internal process risk, system defects risk, technology risk, external factor influence risk; The project risk refers to the risks despite the credit risk when the commercial banks invests in CDM projects, including cyclical risk of CDM project development, risk domestic of examination and approval of CDM project, methodology risk for examination and approval of CDM project, verification risks, registration risks, risks of international climate negotiations and force majeure risks, etc. The author selected 13 indicators as the preliminary evaluation index system, which is composed of the Aim layer (A), the Guideline layer (B), the field layer (C) The indexes in each layer are listed in Table 1.

Table 1. Synthetic risk evaluation index system (layer A-C)

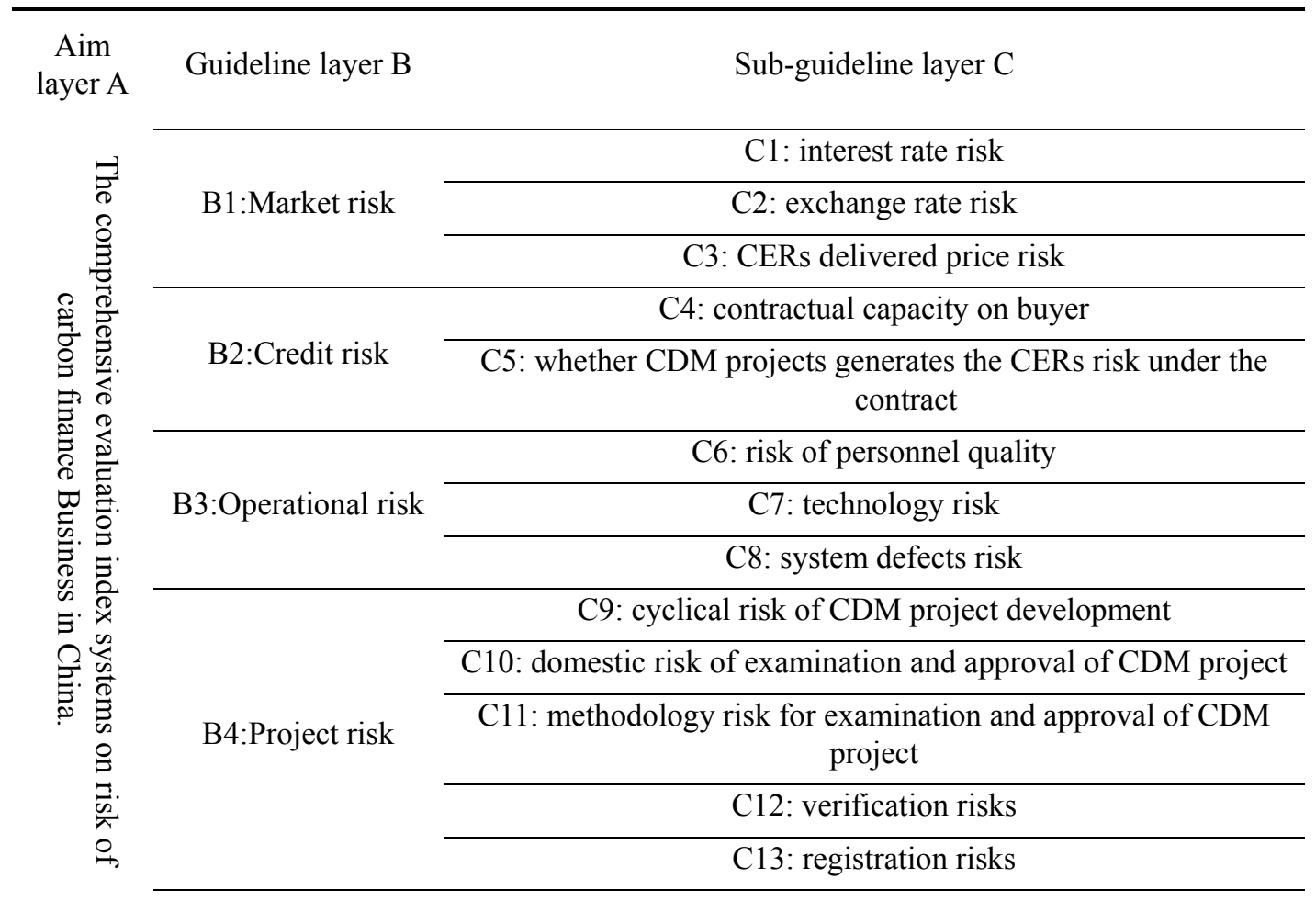




\section{Implementation of Evaluation Algorithm on FAHP}

\subsection{Determinating Evaluation Set}

Before making the comprehensive evaluation, evaluation set must be determinated by experts. Evaluation set in ethnic regions can be set as $F=\left(f_{1}, f_{2}, f_{3}, f_{4}, f_{5}\right)=$ (Superior, Good, Average, Fair, and poor).

\subsection{Setting Relative Importance Indicators and Construting Judgement Matrixs}

After confirmation of index system and evaluation set, experts will assign the relative weights (importance) to indexes. In the FAHP, weights are determined using pair-wise comparison between each pair of criteria. To determine relative weights, decision makers are asked to make pair-wise comparison using a 1-9 preference scale as shown in Table 2.

Table 2. 1-9 scale method

\begin{tabular}{ll}
\hline $1-9$ scale & The relative importance of the two sub-elements \\
\hline 1 & Equally important \\
\hline 3 & Moderately important with one over another \\
\hline 5 & Strongly important \\
\hline 7 & Very strongly important \\
\hline $2,4,6,8$ & Extremely important \\
\hline
\end{tabular}

According the above scales, exports will confirm Field layer $C_{i}$ relative to $C_{j}$ as well as value of relative importance $m_{i j}$, all of the relative weights construct judgment matrix. According to 9 scale method, judgment matrix is reciprocal. Therefore, the relative importance with the number of $n(n-1) / 2$ given by experts would construct the following fuzzy judgment matrix M:

$$
M=\left[\begin{array}{cccc}
m_{11} & m_{12} & \ldots & m_{1 n} \\
m_{21} & m_{22} & \ldots & m_{2 n} \\
\vdots & \vdots & & \vdots \\
m_{n 1} & m_{n 2} & \ldots & m_{n n}
\end{array}\right]
$$

Where $m_{i i}=1, i=1,2, \ldots, n ; m_{i j}=1 / m_{j i}, i, j=1,2, \ldots, n$

\subsection{Calculating Index Weight}

The Synthetic Evaluation of Index System on Coordinated Development of Ethnic Regions in China is more complex than other regions due to its own features, It is very difficult to estimate consistency, sometime inconsistency would appear in fuzzy judgment matrix, therefore it is necessary to modify consistency in the matrix. Making statistical test about uniformity, the value of $C I$ is an index evaluating the departure of judgment matrix from uniformity: $C I=\left(\lambda_{\max }-n\right) /(n-1)$. For higher dimensional judgment matrix $M$, we usually use the adjusted test standards as $C R=C I / R I$, If $C R<0.1$, it shows that judgment matrix has uniformity. Otherwise, the judgment matrix must be adjusted.

Based on the row data of fuzzy judgment matrix $M=\left[m_{i j}\right]$, we construct consistency judgment matrix with $\mathrm{n}$ groups $M_{i}=\left(m_{k l}^{i}\right)_{n \times n}(i, k, l=1,2, \ldots, n)$. 


$$
M_{i}=\left[\begin{array}{cccc}
1 & m_{12} & \ldots & m_{1 n} \\
1 / m_{12} & 1 & \ldots & m_{1 n} / m_{12} \\
\vdots & \vdots & & \vdots \\
1 / m_{1 n} & m_{1 n} / m_{12} & \ldots & 1
\end{array}\right]
$$

Then, weights vector of Field layer can be obtained by using square root of sum square method $W_{i}=\left(w_{i 1}, w_{i 2}, \ldots w_{i n}\right)^{T}$. As results, the weights of guideline layer will be as follow:

$$
W=\left[\begin{array}{cccc}
w_{11} & w_{12} & \ldots & w_{1 n} \\
w_{21} & w_{22} & \ldots & w_{2 n} \\
\vdots & \vdots & & \vdots \\
w_{n 1} & w_{n 2} & \ldots & w_{n n}
\end{array}\right]\left[\begin{array}{l}
1 / n \\
1 / n \\
\ldots \\
1 / n
\end{array}\right]=\left\{w_{1}, w_{2}, \ldots, w_{n}\right\}
$$

\subsection{Fuzzy Comprehesive Evaluation}

After confirming the evaluation set, fuzzy adjustment matrix $P_{i}$ between each indicator of guideline layer $B_{i}$ and evaluation set $F$ can be set, on the basis of the $P_{i}$, evaluation results of indicator of guideline layer can be calculated as:

$$
Y_{i}=W_{i} \cdot P_{i}=\left(w_{i 1}, w_{i 2}, \ldots, w_{i h}\right) \cdot\left[\begin{array}{cccc}
p_{i 11} & p_{i 12} & \ldots & p_{i 1 k} \\
p_{i 21} & p_{i 22} & \ldots & p_{i 2 k} \\
\vdots & \vdots & & \vdots \\
p_{i k 1} & p_{i k 2} & \cdots & p_{i h k}
\end{array}\right]=\left\{y_{i 1}, y_{i 2}, \ldots, y_{i k}\right\}
$$

Where $h$ refer to indicator of guideline layer, $B_{i}$ is numbers of lower indicator. Normalizing $Y_{i}$, we have

$$
Y_{i}^{*}=\left(\frac{y_{i 1}}{\sum_{j=1}^{k} y_{i j}}, \cdots \frac{y_{i k}}{\sum_{j=1}^{k} y_{i j}}\right)=\left(y_{i 1}{ }^{*}, y_{i 2}{ }^{*}, \ldots, y_{i k}{ }^{*}\right)
$$

Fuzzy adjustment matrix between indicator set of guideline layer and evaluation set $F$ should be:

$$
P=\left[\begin{array}{cccc}
y_{11}{ }^{*} & y_{12}{ }^{*} & \cdots & y_{1 k}{ }^{*} \\
y_{21}{ }^{*} & y_{22}{ }^{*} & \cdots & y_{2 k}{ }^{*} \\
\vdots & \vdots & \vdots & \vdots \\
y_{n 1}{ }^{*} & y_{n 2}{ }^{*} & \cdots & y_{n k}{ }^{*}
\end{array}\right]
$$

Then, evaluation results of Aim layer can express as:

$$
Y=W \cdot P=\left(w_{1}, w_{2}, \ldots, w_{n}\right) \cdot\left[\begin{array}{cccc}
y_{11}{ }^{*} & y_{12}{ }^{*} & \ldots & y_{1 k}{ }^{*} \\
y_{21}{ }^{*} & y_{22}{ }^{*} & \ldots & y_{2 k}{ }^{*} \\
\vdots & \vdots & \vdots & \vdots \\
y_{n 1}{ }^{*} & y_{n 2}{ }^{*} & \ldots & y_{h k}{ }^{*}
\end{array}\right]=\left\{y_{1}, y_{2}, \ldots, y_{k}\right\}
$$

Normalizing $Y$, we have

$$
Y^{*}=\left(\frac{y_{1}}{\sum_{j=1}^{k} y_{j}}, \cdots \frac{y_{k}}{\sum_{j=1}^{k} y_{j}}\right)=\left(y_{1}{ }^{*}, y_{2}{ }^{*}, \ldots, y_{k}{ }^{*}\right)
$$

Based on the above, it is easy to obtain final ranks of the synthetic evaluation.

\subsection{Empirical Analysis}

According to above evaluation model and the index system of synthetic evaluation, exports firstly construct judgment matrix by comparing two-pair indicators, and calculate relative weights between Aim layer and Guideline layer, the judgment matrix of Guideline layer will be: 


$$
B_{1}=\left[\begin{array}{ccc}
1 & 1 / 3 & 1 / 6 \\
3 & 1 & 1 / 5 \\
6 & 5 & 1
\end{array}\right] \quad B_{2}=\left[\begin{array}{cc}
1 & 6 \\
1 / 6 & 1
\end{array}\right] \quad B_{3}=\left[\begin{array}{ccc}
1 & 7 & 6 \\
1 / 7 & 1 & 1 / 2 \\
1 / 6 & 2 & 1
\end{array}\right] \quad B_{4}=\left[\begin{array}{ccccc}
1 & 1 / 3 & 1 / 6 & 1 / 8 & 1 / 7 \\
3 & 1 & 1 / 4 & 1 / 7 & 1 / 6 \\
6 & 4 & 1 & 1 / 6 & 1 / 5 \\
8 & 7 & 6 & 1 & 2 \\
7 & 6 & 5 & 1 / 2 & 1
\end{array}\right]
$$

Using 120 samples from investigated data, we get the Table 3:

Table 3. Evaluation indicators set for synthetic risk index system

\begin{tabular}{|c|c|c|c|c|c|c|}
\hline \multirow{2}{*}{$\begin{array}{l}\text { Guideline } \\
\text { layer B }\end{array}$} & \multirow{2}{*}{$\begin{array}{l}\text { Field } \\
\text { layer C }\end{array}$} & \multicolumn{5}{|c|}{ Evaluation set } \\
\hline & & Superior & Good & Average & Fair & Poor \\
\hline \multirow{3}{*}{ B1 } & $\mathrm{C} 1$ & 23 & 26 & 28 & 3 & 0 \\
\hline & $\mathrm{C} 2$ & 18 & 33 & 9 & 18 & 2 \\
\hline & $\mathrm{C} 3$ & 15 & 26 & 17 & 21 & 1 \\
\hline \multirow{2}{*}{$\mathrm{B} 2$} & $\mathrm{C} 4$ & 13 & 18 & 22 & 25 & 2 \\
\hline & $\mathrm{C} 5$ & 10 & 10 & 25 & 14 & 4 \\
\hline \multirow{3}{*}{ B3 } & $\mathrm{C} 12$ & 21 & 26 & 17 & 13 & 3 \\
\hline & $\mathrm{C} 13$ & 22 & 30 & 19 & 8 & 1 \\
\hline & $\mathrm{C} 14$ & 12 & 17 & 26 & 18 & 7 \\
\hline \multirow{5}{*}{ B4 } & $\mathrm{C} 15$ & 16 & 18 & 28 & 15 & 3 \\
\hline & $\mathrm{C} 16$ & 12 & 24 & 21 & 8 & 5 \\
\hline & $\mathrm{C} 17$ & 20 & 25 & 22 & 10 & 3 \\
\hline & $\mathrm{C} 4$ & 13 & 18 & 22 & 25 & 2 \\
\hline & $\mathrm{C} 5$ & 10 & 10 & 25 & 14 & 4 \\
\hline
\end{tabular}

According to the above evaluation model and data, we get the synthetic evaluation $Y^{*}=(0.211,0.305,0.292,0.140,0.052)$. The result shows that the integration situation for coordinated development in ethnic regions is normal and in good reliability.

\section{Conclusions}

An index evaluation system for comprehensive evaluation on risk of carbon finance Business in China is constructed by AHP Algorithm. The ideas in this paper are unique and different from those in the literature. Although it should be noted that the evaluation model is mainly based on experts' numerical scoring through a series of mathematical methods with limited accuracy, the results are still helpful in constituting reasonable policy in the process of evaluation on risk of carbon finance Business in China.

\section{References}

L. R. Yan, Y. W. Lai, B. Zhang, \& Z. L. Li. (2009). Boosting Low-Carbon Economic Development of the Green Financial Innovations. Fujian Finance, (12), 4-8.

Miao, Xiaoyu. (2010). Carbon finance risk nalysis and the response of Chinese commercial Banks. Journal of rural financial research, (9), 12-16

P. Krugman, \& J. A. Venables. (1995). Globalization and the Inequality of Nations. The Quarterly Journal of Economics, 110(4), 857-880. http://dx.doi.org/10.2307/2946642

Qin, Xueping. (2010). The Development of China's Carbon Finance and Carbon Finance Mechanism Innovation Strategy. Shanghai Finance, (10), 23-29.

R. G. King, \& R. Levine. (1993). Finance and Growth: Schumpeter Might Be Right. The Quarterly Journal of Economics, 108(3), 717-737. http://dx.doi.org/10.2307/2118406

V. Bencivenga, \& B. Smith. (1991). Financial Intermediation and Endogenous Growth. Journal of Review of Economics Studies, 58(2), 195-209. http://dx.doi.org/10.2307/2297964

W. F. Ren. (2008). Low-Carbon Economy and Environment of Financial Innovation. Shanghai Economic Research, (3), 38-42. 